\title{
A study on the knowledge, attitude and practice on adverse drug reactions and pharmacovigilance among post graduate residents in Gandhi Medical College, Bhopal
}

\author{
Mukesh Hindoliya, Faizan Chitapure*
}

Department of Pharmacology, Gandhi Medical College, Bhopal, Madhya Pradesh, India

Received: 06 July 2019

Revised: 16 August 2019

Accepted: 17 August 2019

*Correspondence to:

Dr. Faizan Chitapure,

Email: faizanchitapure @ gmail.com

Copyright: (C) the author(s), publisher and licensee Medip Academy. This is an openaccess article distributed under the terms of the Creative Commons Attribution NonCommercial License, which permits unrestricted noncommercial use, distribution, and reproduction in any medium, provided the original work is properly cited.

\begin{abstract}
Background: Resident doctors should consider adverse drug reaction (ADR) reporting as their professional obligation and should be aware of the existing pharmacovigilance mechanisms in their countries. In India, pharmacovigilance implementation is essential due to the absence of a vibrant ADR monitoring system. The present study primary objective was to evaluate the knowledge, attitude and practices (KAP) of the postgraduate students towards pharmacovigilance and ADR reporting in GMC, Bhopal as they observe and attend to the patients round the clock while the patient is admitted in the hospital.

Methods: A cross-sectional-observational study was carried out using a pretested questionnaire having 17 questions in all. Data was compiled, entered in Microsoft Excel sheet and analysed by descriptive statistics.

Results: A total of 127 duly filled responses were analysed. Study shows ADR is necessary and Pharmacovigilance should be taught in detail to postgraduate students is an important finding from our study. In this study there was also a wide gap between the ADR experienced in professional practice $(71 \%)$ and ADR reported $(23 \%)$.

Conclusions: In our present study, the average knowledge score was $64 \%$ in contrast to $32 \%$ residents who didn't answered correctly. Though majority $(87 \%)$ of the residents had a positive attitude towards awareness about Pharmacovigilance and ADR reporting, however in clinical scenario even as ADR reporting was considered to be important by a large majority of the participants, the actual practices of ADR reporting was very low.
\end{abstract}

Keywords: Pharmacovigilance, Adverse drug reaction reporting, Postgraduate students, KAP study

\section{INTRODUCTION}

Adverse drug reactions (ADRs) are noxious, undesirable and unintended effects of drug administered at doses used for prophylaxis, diagnosis or therapy, and may be the major cause of morbidity, mortality and also increases the cost of the healthcare of the patient, health institutions as well as community. ${ }^{1}$ ADRs are negative consequences of drug therapy, which are also responsible for significant number of hospital admissions and frequent physician or hospital visits. All drugs have inherent risk of producing adverse effects so whenever a drug is given a risk is taken. The incidence of ADRs varies $6-7 \%$ of all hospitalized patients and may be $10-20 \%$ of all patients taking drug therapy. Recent epidemiological studies estimated that ADRs are fourth to sixth leading cause of death. $^{2}$ It is one of the leading cause of morbidity and mortality with an estimated economic burden of about 30 billion to 130 billion US dollars annually. The study also showed that the average cost involved in treating these ADRs was INR 900/- (USD 15\$) per patient. ${ }^{3}$

Pharmacovigilance (PV) is defined as the science and activities relating to the detection, assessment, 
understanding and prevention of adverse effects or any other drug-related problem. WHO established its Programme for International Drug Monitoring in response to the thalidomide disaster detected in 1961. Together with the WHO Collaborating Centre for International Drug Monitoring, Uppsala, WHO promotes PV at the country level. At the end of 2010, 134 countries were part of the WHO PV Programme. The aims of PV are to enhance patient care and patient safety in relation to the use of medicines; and to support public health programmes by providing reliable, balanced information for the effective assessment of the risk-benefit profile of medicine. ${ }^{4}$

To detect and spontaneously report ADR and to ensure drug safety, National Pharmacovigilance Program was initiated in India in the year 2004, under aegis of Ministry of health and Family welfare, Government of India with All India Institute of Medical Sciences (AIIMS), New Delhi as a National Coordinating Center (NCC) to monitor ADR. ${ }^{5,6}$ For more effective way to implementation of this program, recently NCC shifts from AIIMS, New Delhi to the Indian Pharmacopoeia Commission, Ghaziabad, (UP) in April, 2011 under aegis of Uppsala Monitoring Center-World Health Organization (UMC-WHO). The advantage of pharmacovigilance program includes the detection of medicines of substandard quality as well as prescribing pattern and administration errors. This program is essential due to the absence of a vibrant ADR monitoring system and also lack of a reporting culture among health care professional in India.?

The success of a pharmacovigilance program depends upon the active involvement of the healthcare professionals such as doctors, pharmacist, nurses. ${ }^{8,9}$ With adequate knowledge and practices of pharmacovigilance and ADR reporting in India, there will be not only increasing reporting of $\mathrm{ADR}$, but also reducing incidence rate as well as health care cost of patient and also banned harmful drug to the patient in actual clinical practices.

Although it has shown some improvement, but still lot is required to be done to increase the spontaneous reporting. Spontaneous reporting of ADR by health care professionals is backbone of pharmacovigilance program, but under reporting of ADR is still prevalent and is the cause of concern. Study showed that only $6-10 \%$ of all ADR cases are reported. Health care professional has a major role in pharmacovigilance program. ${ }^{10}$ Therefore, the study was planned and primary objective was to evaluate the knowledge, attitude and practices (KAP) toward pharmacovigilance and ADRs reporting in postgraduate students of Gandhi Medical College, Bhopal because resident doctors observe and attend to the patients round the clock while the patient is admitted in the hospital.

\section{METHODS}

The study was planned to be conducted in the month of April 2019, with filling of questionnaire by resident doctors on a single working day (10 ${ }^{\text {th }}$ April 2019) followed by evaluation of data and compilation of result in next 20 days. After applying and obtaining approval from the Institutional Ethics Committee (IEC) of the college, a questionnaire-based cross-sectionalobservational study was conducted among all the postgraduate students on duty in Gandhi Medical College and affiliated hospitals viz Hamidia Hospital, Kamla Nehru Hospital and Sultania Zanana hospital, Bhopal on $10^{\text {th }}$ April 2019. The study participants consisted of all the postgraduate students who gave their informed consent and who were working at the hospital during the study period. KAP questionnaire was designed to assess the demographic details of the resident doctors, their knowledge of pharmacovigilance, attitudes towards pharmacovigilance, and their practice on ADR reporting. Pretesting of questionnaire was done on 12 randomly selected health professionals of the institute. The questionnaire was finalized after ambiguous and unsuitable questions were modified based on the result of pretest. There were 17 questions in all (six related to knowledge, four related to attitude, and seven related to practice). One question was even asked to determine the reasons for underreporting. The questionnaire was handed to the students after explaining the purpose of the study. These questions were designed based on earlier studies for assessing KAP of ADR reporting. ${ }^{11-15}$ Any doubts regarding questionnaire were clarified by investigator. $25 \mathrm{~min}$ was given for filling the questionnaire. Of total of questionnaires that were submitted by the post graduate doctors, data was compiled, entered in Microsoft Excel sheet and analysed by descriptive statistics, and result was computed regarding the knowledge, attitude and practice of pharmacovigilance and ADR reporting by postgraduate students.

\section{RESULTS}

A total of 150 questionnaires were distributed among the postgraduate students of which 127 were returned, giving a response rate of $85 \%$. Out of the total $(n=127)$ postgraduate students responded, $52 \%$ were males (66) and $48 \%$ were females (61) residents (Figure 1).

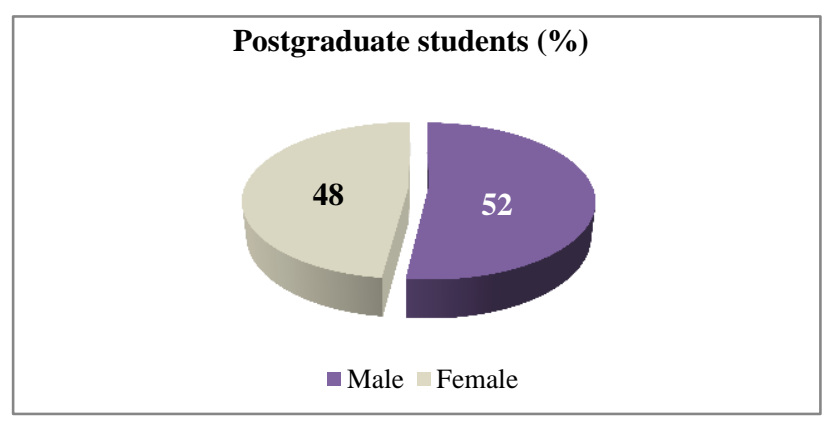

Figure 1: Postgraduate students respond.

The questionnaire consisted of six questions related to knowledge of postgraduate students about pharmacovigilance and ADRs. Of the total $(n=127)$ filled 
questionnaires received, at an average 64\% residents correctly answered the questions in contrast to $32 \%$ residents who didn't answered correctly while those who weren't aware about the topic or didn't choose to answer constituted $4 \%$ of the questionnaires (Table 1).

Table 1: Knowledge of postgraduate students about pharmacovigilance and ADRs.

\begin{tabular}{|llllllll|}
\hline S. No. & Question & Yes & Yes (\%) & No & No (\%) & Don't know & Don't know (\%) \\
$\mathbf{1}$ & $\begin{array}{l}\text { Are you aware of National } \\
\text { Pharmacovigilance Programme } \\
\text { of India? }\end{array}$ & 74 & 58 & 43 & 34 & 10 & 8 \\
\hline $\mathbf{2}$ & $\begin{array}{l}\text { Are you aware of } \\
\text { Pharmacovigilance Committee } \\
\text { in your Institute? }\end{array}$ & 64 & 50 & 60 & 48 & 3 & 2 \\
\hline $\begin{array}{l}\text { Question } \\
\mathbf{3}\end{array}$ & What is Pharmacovigilance? & 84 & 66 & 41 & 32 & 2 & 2 \\
\hline $\mathbf{4}$ & $\begin{array}{l}\text { Main objective of } \\
\text { Pharmacovigilance }\end{array}$ & 56 & 44 & 65 & 51 & 6 & 5 \\
\hline $\mathbf{5}$ & $\begin{array}{l}\text { Who can report ADRs in a } \\
\text { hospital? }\end{array}$ & 117 & 92 & 8 & 6 & 2 & 2 \\
\hline $\mathbf{6}$ & $\begin{array}{l}\text { Which regulatory body is } \\
\text { responsible for monitoring } \\
\text { ADRs in India? }\end{array}$ & 91 & 72 & 28 & 22 & 8 & 6 \\
\hline & Total & 64 & & 32 & No response \\
\hline
\end{tabular}

Table 2: Practices of postgraduate students toward ADRs.

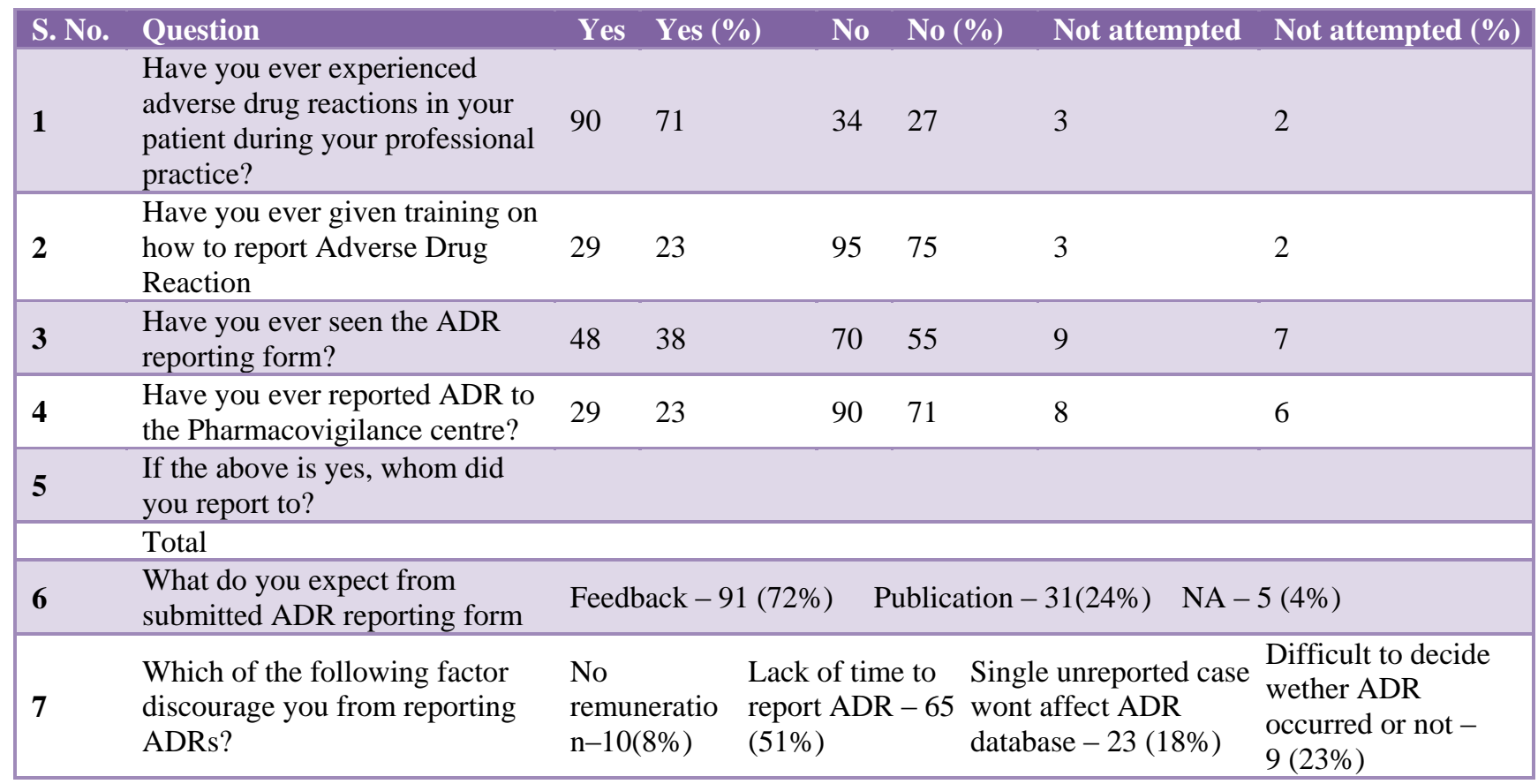

The questionnaire consisted of seven questions related to practices of postgraduate students toward ADRs. Of the total $(\mathrm{n}=127)$ filled questionnaires received, at an average only $39 \%$ residents have experienced and practiced reporting $\mathrm{ADR}$ in contrast to $57 \%$ residents who didn't clinically experience or reported ADR while those who weren't aware about the topic or didn't choose to answer constituted $4 \%$ of the questionnaires. The factors discouraging participants from reporting ADRs were no remuneration $(8 \%)$, lack of time to report $\mathrm{ADR}(51 \%)$, belief that a single unreported case may not affect ADR database (18\%), and difficulty to decide whether ADR has occurred or not $(23 \%)$ (Table 2$)$.

The questionnaire consisted of four questions related to postgraduate students attitude toward Pharmacovigilance And ADRs reporting. Of the total $(n=127)$ filled questionnaires received, at an average majority $(87 \%)$ of the residents had a positive attitude towards awareness about Pharmacovigilance and ADR reporting with only 
$2 \%$ residents responding negatively while around $11 \%$ postgraduate students had a neutral attitude towards ADR reporting (Table 3 ).
In this study there was also a wide gap between the ADR experienced in professional practice $(71 \%)$ and ADR reported $(23 \%)$ by resident doctors showing the need of bringing Pharmacovigilance in practice (Figure 2).

Table 3: Postgraduate student's attitude toward pharmacovigilance and ADRs reporting.

\begin{tabular}{|c|c|c|c|c|c|c|c|c|c|}
\hline $\begin{array}{l}\text { S. } \\
\text { No. }\end{array}$ & Question & Yes & $\begin{array}{l}\text { Yes } \\
(\%)\end{array}$ & No & $\begin{array}{l}\text { No } \\
(\%)\end{array}$ & $\begin{array}{l}\text { May } \\
\text { be }\end{array}$ & $\begin{array}{l}\text { May } \\
\text { be } \\
(\%)\end{array}$ & $\begin{array}{l}\text { Cant } \\
\text { say }\end{array}$ & $\begin{array}{l}\text { Cant } \\
\text { say }(\%)\end{array}$ \\
\hline 1 & $\begin{array}{l}\text { Do you think to improve reporting, } \\
\text { pharmacovigilance workshop / training should be } \\
\text { provided to you }\end{array}$ & 117 & 92 & 8 & 6 & 1 & 1 & 1 & 1 \\
\hline 2 & $\begin{array}{l}\text { Do you think ADR reporting is beneficial for clinical } \\
\text { practice }\end{array}$ & 122 & 96 & 3 & 2 & 1 & 1 & 1 & 1 \\
\hline 3 & $\begin{array}{l}\text { Do you think reporting of adverse drug reaction is } \\
\text { necessary }\end{array}$ & 113 & 89 & 1 & 1 & 5 & 4 & 8 & 6 \\
\hline 4 & $\begin{array}{l}\text { What do you think, should ADR reporting be made } \\
\text { mandatory? }\end{array}$ & 89 & 70 & 0 & 0 & 21 & 17 & 17 & 13 \\
\hline
\end{tabular}

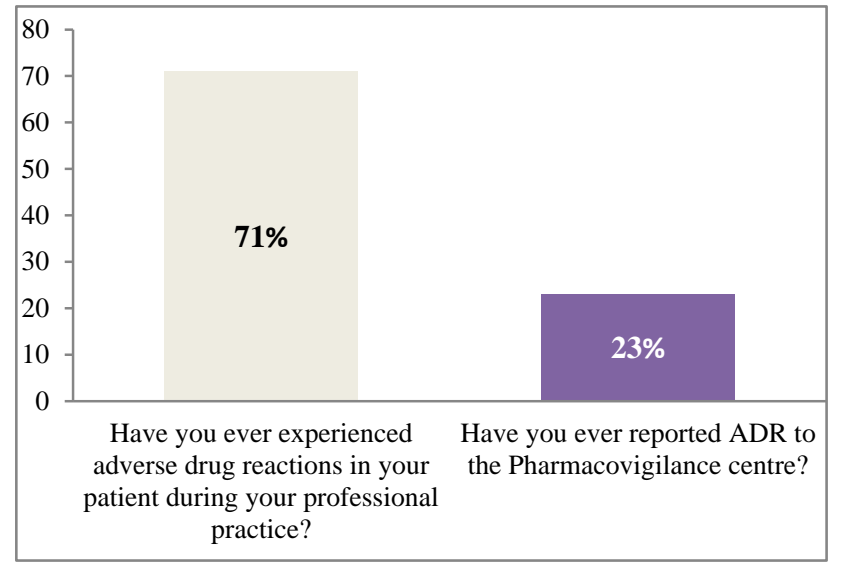

Figure 2: Gap between the ADR experienced in professional practice and ADR reported by resident.

\section{DISCUSSION}

Pharmacovigilance is an integral part of holistic health care as it helps in detection and prevention of ADR of medicinal products. Reporting ADRs is an essential component of pharmacovigilance programme. Spontaneous reporting system is important method for reporting ADR and also ADR because of newer drug.

In the present study, we observed that there was a lack of correct knowledge about ADRs reporting and Pharmacovigilance among the post graduate doctors. The average knowledge score was $64 \%$ in contrast to $32 \%$ residents who didn't answered correctly and it indicates that there is still a need to educate and sensitize postgraduate students about knowledge and importance of ADR reporting and Pharmacovigilance.

The fact that majority of respondents agreed that reporting of ADR is necessary and pharmacovigilance should be taught in detail to postgraduate students is an important finding from our study. In this study there was also a wide gap between the ADR experienced in professional practice $(71 \%)$ and ADR reported $(23 \%)$ by resident doctors showing the need of bringing Pharmacovigilance in practice.

In resemblance to our study, study conducted at Mysore, and Muzzafarnagar has also shown adequate knowledge but poor practice for ADR among prescribers. Another similar study at Mumbai, shows high knowledge but poor practices for ADRs reporting in doctors. ${ }^{16-18}$

In our study, the factors discouraging participants from reporting ADRs were no remuneration (8\%), lack of time to report ADR $(51 \%)$, belief that a single unreported case may not affect ADR database (18\%), and difficulty to decide whether ADR has occurred or not $(23 \%)$. In a similar study done at Spain, the major problem for underreporting of ADRs were identified to be difficulty in diagnosis of ADRs, lack of knowledge regarding the ADR reporting system, clinical workload on the doctors, a concern for patient confidentiality and possible legal implications of reporting. ${ }^{19}$

In our present study, though majority (87\%) of the residents had a positive attitude towards awareness about Pharmacovigilance and ADR reporting with only 2\% residents responding negatively, however in clinical scenario even as ADR reporting was considered to be important by a large majority of the participants, the actual practices of ADR reporting was very low.

\section{ACKNOWLEDGEMENTS}

Authors are thankful to Dr. M. P. Shukla (Professor \& Head), Dr. Arun Srivastav (Professor), Dr. J. L. Marko (Professor), Dr. Hemlata Verma (Associate Professor), Dr. Mehul Agarwal (Assistant Professor) Department of Pharmacology, Gandhi Medical College Bhopal for their 
valuable intellectual support and constant motivation in carrying out this work.

Funding: No funding sources

Conflict of interest: None declared

Ethical approval: The study was approved by the Institutional Ethics Committee

\section{REFERENCES}

1. Adverse Drug Events, Adverse Drug Reactions and Medication Errors (FAQs); VA Center for Medication Safety And VHA Pharmacy Benefits Management Strategic Healthcare Group and the Medical Advisory Panel: 2006.

2. Brown SD Jr, Landry FJ. Recognizing, reporting, and reducing adverse drug reactions. South Med J. 2001;94:370-3.

3. Ramesh M, Pandit J, Parthasarathi G. Adverse drug reactions in a south Indian hospital - Their severity and cost involved. Pharmacoepidemiol Drug Saf. 2003;12:687-92.

4. Available at: https://www.who.int/medicines/areas/ quality_safety/safety_efficacy/pharmvigi/en/. Accessed on 3 June 2019.

5. Adithan C. National pharmacovigilance programme. Indian J Pharmacol. 2005;37:34.

6. Pharmacovigilance Programme in India (PvPI)Indian scenario. Available at: http://www.ipc.gov.in/ PvPI/Pv_home.html. Accessed on 7 December 2017.

7. Feely J, Moriarty S, O'Connor P. Stimulating reporting of adverse drug reactions by using a fee. BMJ. 1990;300:22-3.

8. Ahmad SR. Adverse drug event monitoring at the Food and Drug Administration. J Gen Intern Med. 2003;18:57-60.

9. Wysowski DK, Swartz L. Adverse drug event surveillance and drug withdrawals in the United States, 1969-2002: The importance of reporting suspected reactions. Arch Intern Med. 2005;165:1363-9.

10. Shirodkar SN. India become seventh largest contributor to WHO-UMC's drug safety data base. Available at: http://www.pharmabiz.com. Accessed on 22 April 2019.

11. Upadhyaya P, Seth V, Moghe VV, Sharma M, Ahmed M. Knowledge of adverse drug reaction reporting in first year postgraduate doctors in a medical college. Ther Clin Risk Manage. 2012;8:307-12.

12. Remesh A. Identifying the reasons for under reporting of ADR: A cross sectional survey. Res J Pharm Biol Chem Sci. 2012;3:1379-86.

13. Khan SA, Goyal C, Chandel N, Rafi M. Knowledge, attitude and practice of doctors to adverse drug reaction reporting in a teaching hospital in India: An observational study. J Nat Sci Biol Med. 2013;4:1916.

14. Muraraiah S, Rajarathna K, Sreedhar D, Basavalingu $\mathrm{D}$, Jayanthi CR. A questionnaire study to assess the knowledge, attitude and practice of Pharmacovigilance in a paediatric tertiary care centre. J Chem Pharm Res. 2011;3:416-22.

15. Hardeep, Bajaj JK, Kumar R. A survey on the knowledge, attitude and the practice of pharmacovigilance among the health care professionals in a teaching hospital in northern India. J Clin Diagn Res. 2013;7:97-9.

16. Gupta P, Udupa A. Adverse drug reaction reporting and pharmacovigilance: Knowledge, attitudes and perceptions among resident doctors. J Pharm Sci Res. 2011;3:1064-9.

17. Ghosh S, Ali S, Chhabra L, Prasad C, Gupta A. Investigation of attitudes and perception of medical practitioners on adverse drug reaction reporting - A pilot study. Pharma Res. 2010;3:1-9.

18. Chatterjee S, Lyle N, Ghosh S. A survey of the knowledge, attitude and practice of adverse drug reaction reporting by clinicians in eastern India. Drug Saf. 2006;29:641-2.

19. Vallano A, Cereza G, Pedròs C, Agustí A, Danés I, Aguilera C, et al. Obstacles and solutions for spontaneous reporting of adverse drug reactions in the hospital. Br J Clin Pharmacol. 2005;60:653-8.

Cite this article as: Hindoliya M, Chitapure F. A study on the knowledge, attitude and practice on adverse drug reactions and pharmacovigilance among post graduate residents in Gandhi Medical College, Bhopal. Int J Basic Clin Pharmacol 2019;8:2108-12. 